\title{
Corrigendum
}

\section{Corrigendum to "Convergence Analysis of Legendre Pseudospectral Scheme for Solving Nonlinear Systems of Volterra Integral Equations"}

\author{
Emran Tohidi, ${ }^{1}$ O. R. Navid Samadi, ${ }^{1}$ and S. Shateyi ${ }^{2}$ \\ ${ }^{1}$ Young Researchers and Elite Club, Mashhad Branch, Islamic Azad University, Mashhad, Iran \\ ${ }^{2}$ Department of Mathematics and Applied Mathematics, School of Mathematical and Natural Sciences, University of Venda, \\ Private Bag X5050, Thohoyandou 0950, South Africa
}

Correspondence should be addressed to S. Shateyi; stanford.shateyi@univen.ac.za

Received 25 February 2015; Accepted 15 April 2015

Copyright (C) 2015 Emran Tohidi et al. This is an open access article distributed under the Creative Commons Attribution License, which permits unrestricted use, distribution, and reproduction in any medium, provided the original work is properly cited.

In the paper titled "Convergence Analysis of Legendre Pseudospectral Scheme for Solving Nonlinear Systems of Volterra Integral Equations," the affiliation of S. Shateyi was "Institute for Groundwater Studies, Faculty of Natural and Agricultural Sciences, University of the Free State, Bloemfontein 9300, South Africa" and is corrected as above. 


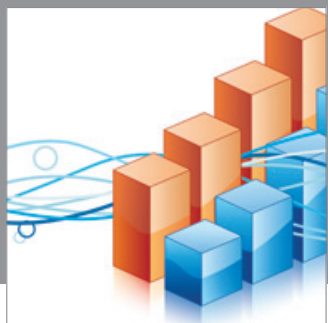

Advances in

Operations Research

mansans

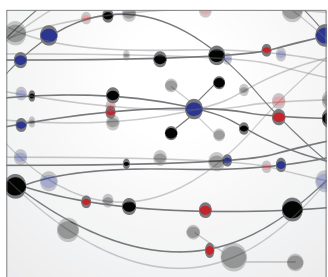

The Scientific World Journal
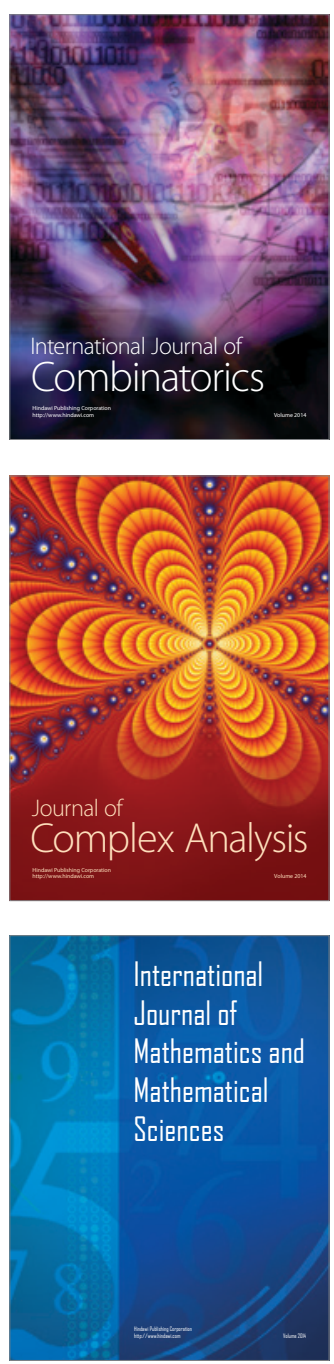
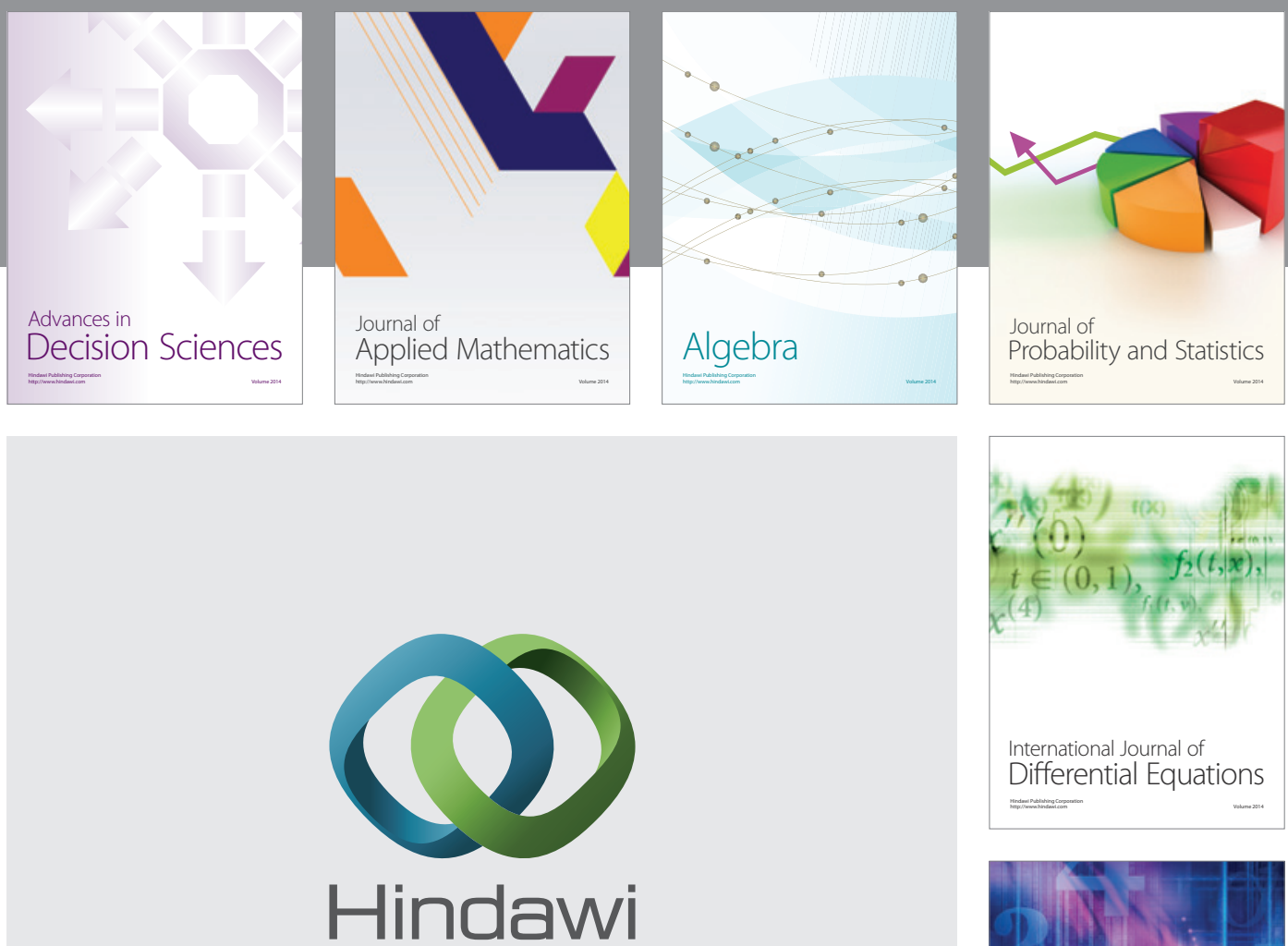

Submit your manuscripts at http://www.hindawi.com
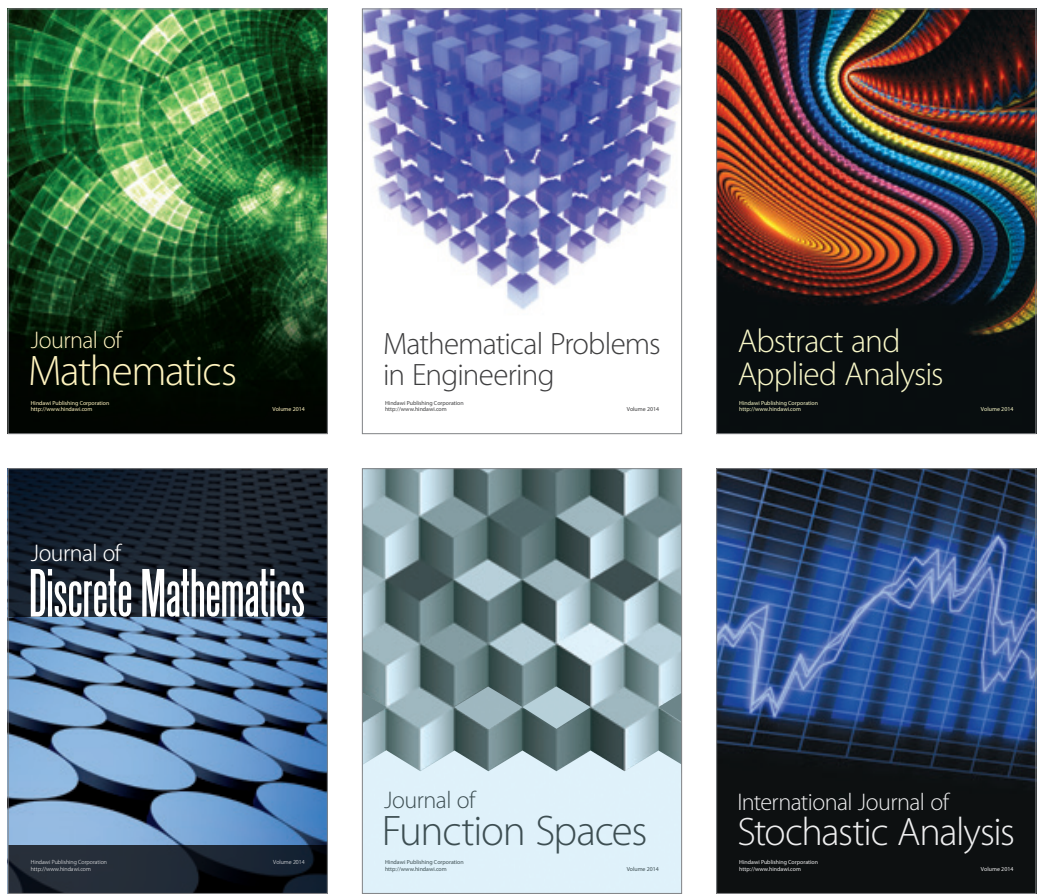

Journal of

Function Spaces

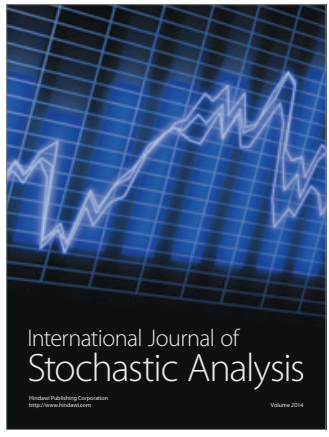

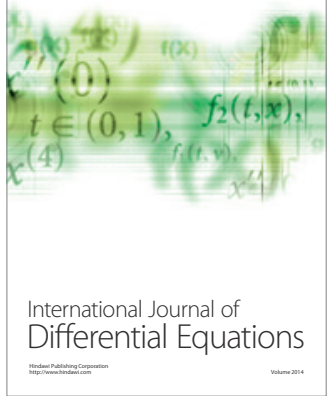
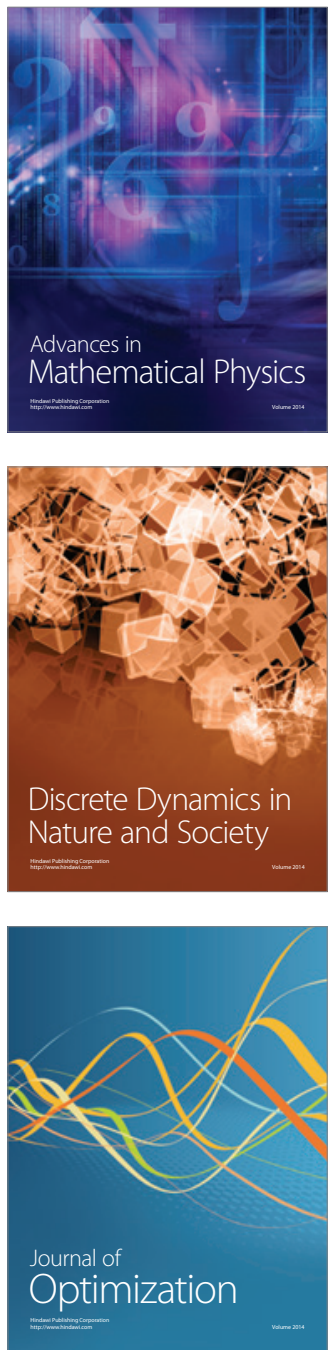